\title{
Maxillofacial injuries in moose-motor vehicle collisions versus other high-speed motor vehicle collisions
}

\author{
Sharon Kim MD ${ }^{1}$, A Robertson Harrop MD MSc FRCSC ${ }^{2}$
}

\begin{abstract}
S Kim, AR Harrop. Maxillofacial injuries in moose-motor vehicle collisions versus other high-speed motor vehicle collisions. Can J Plast Surg 2005;13(4):191-194.
\end{abstract}

BACKGROUND: Anecdotal experience has suggested that there is a higher frequency of maxillofacial injuries among motor vehicle collisions involving moose.

OBJECTIVES: A retrospective cohort study design was used to investigate the incidence of various injuries resulting from moose-motor vehicle collisions versus other high-speed motor vehicle collisions.

METHODS: A chart review was conducted among patients presenting to a Canadian regional trauma centre during the five-year period from 1996 to 2000.

RESULTS: Fifty-seven moose-motor vehicle collisions were identified; 121 high-speed collisions were randomly selected as a control group. Demographic, collision and injury data were collected from these charts and statistically analyzed. The general demographic features of the two groups were similar. Moose collisions were typically frontal impact resulting in windshield damage. The overall injury severity was similar in both groups. Likewise, the frequency of intracranial, spinal, thoracic and extremity injuries was similar for both groups. The group involved in collisions with moose, however, was 1.8 times more likely then controls to sustain a maxillofacial injury $(\mathrm{P}=0.004)$ and four times more likely to sustain a maxillofacial fracture $(\mathrm{P}=0.006)$.

CONCLUSIONS: Occupants of motor vehicles colliding with moose are more likely to sustain maxillofacial injuries than those involved in other types of motor vehicle collisions. It is speculated that this distribution of injuries relates to the mechanism of collision with these large mammals with a high centre of gravity.

Key Words: Accidents; Animal; Facial injuries; Human; Traffic; Wounds and injuries

\section{Les traumatismes maxillofaciaux après une collision entre une automobile et un orignal par rapport à d'autres collisions à haute vitesse en automobile}

\begin{abstract}
HISTORIQUE : L'expérience de cas isolés laisse supposer que les traumatismes maxillofaciaux sont plus fréquents en cas de collisions entre une automobile et un orignal.

OBJECTIFS : Une étude rétrospective de cohortes a été utilisée pour examiner l'incidence de divers traumatismes découlant de collisions entre une automobile et un orignal par rapport à d'autres collisions à haute vitesse en automobile.
\end{abstract}

MÉTHODOLOGIE : L'examen des dossiers des patients s'étant présentés à un centre canadien de traumatologie pendant le quinquennat de 1996 à 2000 a été effectué.

RÉSULTATS : Cinquante-sept collisions entre une automobile et un orignal ont été repérées, et 121 collisions à haute vitesse ont été sélectionnées au hasard pour servir de groupe témoin. Les données démographiques, relatives à la collision et au traumatisme ont été colligées à partir de ces dossiers et ont fait l'objet d'une analyse statistique. Les caractéristiques démographiques générales des deux groupes étaient similaires. Les collisions avec un orignal provoquaient généralement un choc frontal entraînant des dommages au pare-brise. La gravité globale des traumatismes était similaire dans les deux groupes, de même que la fréquence des traumatismes intracrâniens, médullaires, thoraciques et des extrémités. Le groupe impliqué dans une collision avec un orignal était toutefois 1,8 fois plus susceptible de subir un traumatisme maxillofacial $(\mathrm{P}=0,004)$ que le groupe témoin, et quatre fois plus susceptible de subir une fracture maxillofaciale $(\mathrm{P}=0,006)$.

CONCLUSIONS : Les occupants des véhicules automobiles sont plus susceptibles de subir des traumatismes maxillofaciaux dans le cadre d'une collision avec un orignal. On postule que cette répartition des traumatismes découle du mécanisme de la collision avec ces gros mammifères au centre de gravité élevé.

Several published reports (1-5) from the United States, Canada and Sweden describe the injuries sustained by occupants of motor vehicles that collide with moose, elk or deer. These studies, all case series, report that between $43 \%$ and $70 \%$ of the victims' injuries involved the head or face. A case series (3) of moose-motor vehicle collisions in northern New England between 1990 and 1994 reported on 23 subjects, 70\% of whom sustained head and/or face injuries. A case series (5) of fatalities due to collisions between motor vehicles and cloven-hoofed animals (mostly moose) in Sweden between 1976 and 1981 revealed that in 60 of 63 cases, the injuries involved the head or neck. While some of these authors speculated that the distribution of injuries from game accidents differed from those of other involving moose.

${ }^{1}$ Division of Plastic and Reconstructive Surgery, Department of Surgery, University of Western Ontario, London, Ontario; ${ }^{2}$ Division of Plastic Surgery, Department of Surgery, University of Calgary, Calgary, Alberta

Correspondence: Dr A Robertson Harrop, \#102 - 7 Glenbrook Place Southwest, Calgary, Alberta T3E 6 W4.

Telephone 403-571-3157, fax 403-571-3133, e-mail rharrop@shaw.ca 


\begin{tabular}{|c|c|c|c|}
\hline & $\begin{array}{c}\text { Moose, } n=54 \\
\text { (n [\%]) }\end{array}$ & $\begin{array}{c}\text { Control, } n=121 \\
(n[\%])\end{array}$ & $\mathbf{P}$ \\
\hline Driver & $42(74)$ & $69(57)$ & 0.03 \\
\hline Restraint worn & $42(89)$ & $72(60)$ & 0.002 \\
\hline Night-time* & $39(83)$ & $56(51)$ & $<0.01$ \\
\hline Frontal collision ${ }^{\dagger}$ & $43(91)$ & $42(36)$ & $<0.01$ \\
\hline Windshield damaged & $30(56)$ & $15(12)$ & $<0.01$ \\
\hline Roll over & $8(15)$ & $58(48)$ & $<0.01$ \\
\hline
\end{tabular}

${ }^{*}$ Details not recorded in all charts (moose, $n=47$; control, $n=111$ ); ${ }^{\dagger}$ Details not recorded in all charts (moose, $n=47$; control, $n=118$ )

types of motor vehicle accidents, this has not yet been specifically addressed in the existing literature. All of these studies were case series and none compared motor vehicle collisions involving moose with other motor vehicle collisions.

We therefore conducted a retrospective cohort study comparing the incidence of various injury types in moose-motor vehicle collisions with other high-speed motor vehicle collisions. The study was carried out at the Foothills Medical Centre in Calgary, Alberta, which serves as the regional trauma centre for southern Alberta. The geography of Alberta varies from the Rocky Mountains in the western part of the province to the prairies in the east. As of September 1997, there were approximately 232,000 white-tailed deer, 133,000 mule deer, 118,000 moose and 26,000 elk in Alberta (6).

\section{METHODS}

A retrospective cohort study was performed using patient chart records from the Foothills Medical Centre for the five-year period from January 1, 1996, to December 31, 2000. These charts included patients admitted to the hospital, as well as those treated in the emergency department and discharged without admission to hospital. The Foothills Medical Centre is the sole tertiary regional trauma centre for the southern portion of the province of Alberta.

International Classification of Disease, Ninth Revision (ICD-9) E-codes (7) were used to identify all patients involved in highspeed motor vehicle collisions with moose, deer or elk ('moose' group) for the five-year period. Specifically, charts with the E-code 815 were requested. These charts were, in turn, examined individually by hand to verify their suitability for inclusion into this study group. After exclusion of nonapplicable charts, 57 patients were identified for inclusion in the moose group.

The control group consisted of a random sample of patients involved in all other types of high-speed motor vehicle collisions. It was calculated that with a control group consisting of 120 patients, the study would have a power of $88 \%$ to detect a twofold difference in incidence of maxillofacial injury in moose group patients versus control patients $(a l p h a=0.05)$. Control patients were initially identified by random sampling of all motor vehicle traffic collision patients labelled by the ICD 9 E-codes $811,812,813,814,815,816$ and 819 . The random sample was generated using the terminal two digits of the patient hospital number. These charts were then examined by hand to exclude any patients who were already part of the moose group, were involved in low speed collisions (less than $60 \mathrm{~km} / \mathrm{h}$ ), sustained injuries from another unrelated injury mechanism or were pregnant. Using this sampling process, 339 charts were initially randomly selected from a total of 9693 patients (over the period from January 1, 1996 to
December 31, 2000). Of these, 218 were excluded according to the exclusion criteria, yielding 121 control patients who were involved in high-speed motor vehicle collisions but not involving moose, deer or elk.

Similar data were collected from the charts of both study groups. Demographic data included the patient's age and sex. Collision details included the time and date of collision, the patient's position in the vehicle, the use of restraints, the mechanism of collision and the ensuing damage to the vehicle. The lighting at the time of collision was estimated based on information from the Herzberg Institute of Astrophysics, National Research Council of Canada (8). Calgary's geographical location was used to determine the time of sunrise and sunset. Civil twilight was used to define dawn and dusk. Seasons of the year were defined according to the equinoxes and solstices reported by the US Naval Observatory (9). Collision outcome measures included type and length of admission to hospital, injuries sustained and fatalities. Injuries were subclassified into maxillofacial, intracranial, spinal, thoracic, abdominal and extremity groups. The Abbreviated Injury Score (10) of the most severely injured region was then applied to each case.

Statistical analysis for hypothesis testing was performed using the $\chi^{2}$ test of association. In cases in which contingency tables had small values, Fisher's exact test was used. $\mathrm{P}<0.05$ was considered statistically significant. RRs (moose versus control) with $95 \%$ CIs were also calculated. Mean values where stated are reported as mean \pm SD. Statistical analysis was carried out using Stata Statistical Software (Stata Corporation, USA) (11).

Ethical approval for the study was obtained from the Conjoint Ethics Review Board of the University of Calgary, Calgary, Alberta.

\section{RESULTS}

The 57 patients in the moose group were involved in 54 motor vehicle collisions with moose, elk or deer. Three pairs of patients were from the same vehicles. Of the 54 animals impacted, 16 were moose, 10 were elk and 28 were deer.

The general demographic features of the moose and control groups were not statistically different. The average age of the moose group was $36 \pm 17$ years (range 14 to 80 years), while the average of the control group was $33 \pm 15$ years (range 15 to 78 years) $(\mathrm{P}=0.25)$. Sixty per cent and $65 \%$ of the moose and control groups, respectively, were male $(\mathrm{P}=0.47)$.

Some differences in collision details between the two study groups were noted (Table 1). A larger proportion of patients injured in moose collisions were driving and wearing a restraint. A larger proportion of moose collisions occurred at night, involved frontal impact and resulted in windshield damage. Rollovers occurred in a greater proportion of control patients.

A gradual increase in the number of collisions was seen in both groups over the study period, from 1996 to 2001 (Figure 1). The seasonal frequency of collisions was similar, with the majority of both moose and control collisions occurring during summer and autumn (Figure 2). There was no statistical difference between the two groups in the proportion of collisions occurring between $60 \mathrm{~km} / \mathrm{h}$ and $80 \mathrm{~km} / \mathrm{h}$ and at speeds greater than $80 \mathrm{~km} / \mathrm{h}$ (data not shown).

Collision outcomes in the two groups are shown in Table 2. The proportion of patients with no significant injury was similar in both groups. The proportions of patients in each group with Abbreviated Injury Scores in the aggregated mild (includes none to moderate) and severe (includes severe to 


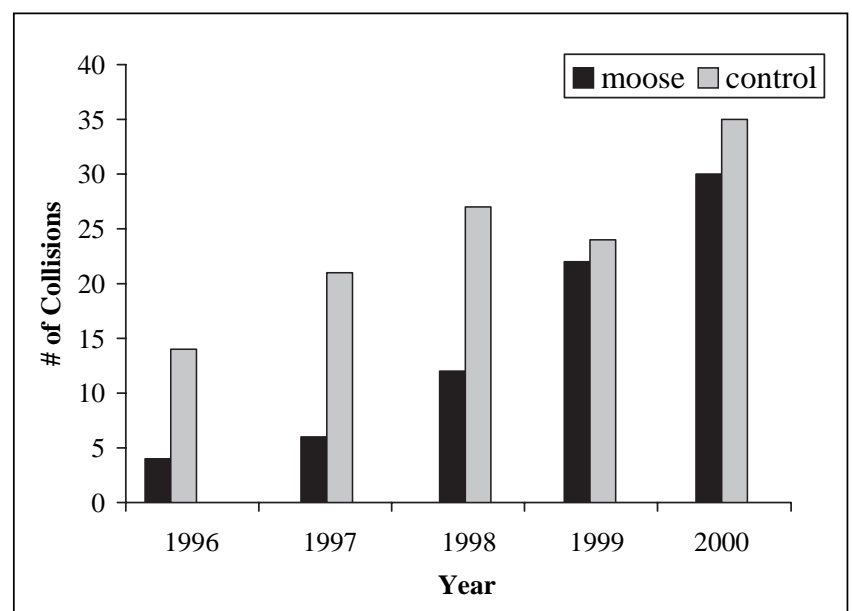

Figure 1) Collisions per year involving moose and motor vehicles

fatal) categories were also similar. There was, however, a statistically higher admission rate in the control group (60\% versus $39 \%$ in moose collisions, $\mathrm{P}=0.01$ ). Considering specific subtypes of injury, there was no statistical difference between groups in the frequency of intracranial, spinal, thoracic or extremity injuries. Control patients had statistically more abdominal injuries ( $14 \%$ versus $2 \%$ in moose group, $\mathrm{P}=0.01$ ).

A significantly greater proportion of moose patients sustained maxillofacial injuries. Specifically, the RR of any maxillofacial injury (moose versus control patients) was $1.80(49 \%$ of the moose group versus $28 \%$ of the control group, $\mathrm{P}=0.004$ ). Even more significantly, the RR of maxillofacial fracture (moose versus control patients) was 4.2 (18\% of the moose group versus $4 \%$ of the control group, $\mathrm{P}=0.006)$. In the moose group, fractures included two frontal bone fractures, eight midface fractures and one mandibular fracture. In addition, three patients sustained fractures to both the frontal bone and midface, while two others fractured both the midface and mandible. In the control group, there were four midface fractures and one mandibular fracture.

\section{DISCUSSION}

The present study compared injuries sustained by those involved in moose-motor vehicle collisions with a control group consisting of a random sample of other high-speed motor vehicle collisions. The age and sex characteristics of the groups were similar. This is expected, because the moose group is essentially a subset of all high-speed motor vehicle collisions. The increasing numbers of motor vehicle collisions over time seen in both the moose group and the control group parallels the increasing frequency of injury collisions reported by the Alberta government (12). The distribution of types of animal involved in these collisions reflects their relative numbers in Alberta.

The finding that collisions with moose occurred more frequently at night has been reported by others $(1,3-5)$ and may relate to the animals being more active at night and drivers having reduced visibility. The higher number of moose collisions during the summer months may relate to more drivers on the road and an increased number of animals feeding on roadside vegetation and escaping the heat and flies found deeper in the forest (13). The great majority of moose collisions involved frontal impact on the vehicle and most had windshield damage,

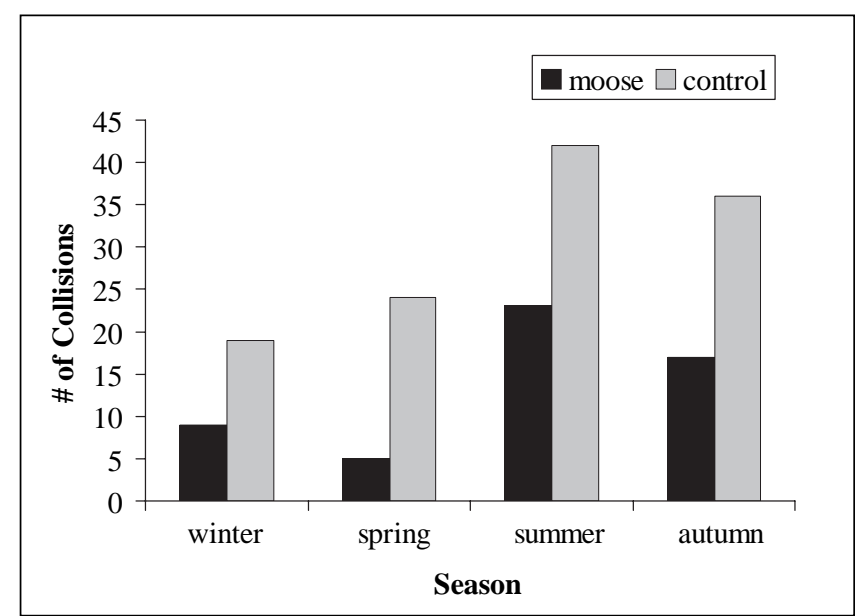

Figure 2) Collisions per season involving moose and motor vehicles

TABLE 2

Collision outcomes in moose-motor vehicle collisions versus other high-speed motor vehicle collisions (control)

\begin{tabular}{lcccc}
\hline & $\begin{array}{c}\text { Moose, } \\
\mathbf{n = 5 7} \\
\mathbf{( n ~ [ \% ] )}\end{array}$ & $\begin{array}{c}\text { Control, } \\
\mathbf{n = 1 2 1} \\
\mathbf{( n ~ [ \% ] )}\end{array}$ & $\mathbf{R R}(\mathbf{9 5 \%} \mathbf{C l )}$ & $\mathbf{P}$ \\
\hline No injury $^{*}$ & $14(25)$ & $32(26)$ & $0.93(0.54-1.60)$ & 0.79 \\
Abbreviated Injury Score $^{\dagger}$ & & & & \\
$\quad$ Mild & $38(67)$ & $76(63)$ & $1.06(0.84-1.33)$ & 0.74 \\
$\quad$ Severe & $19(33)$ & $45(37)$ & $0.90(0.58-1.38)$ & 0.74 \\
Hospital admission & $22(39)$ & $72(60)$ & $0.64(0.45-0.93)$ & 0.01 \\
Specific injuries & & & & \\
$\quad$ Intracranial & $18(32)$ & $42(35)$ & $0.91(0.58-1.43)$ & 0.68 \\
$\quad$ Spinal & $8(14)$ & $26(21)$ & $0.65(0.32-1.35)$ & 0.24 \\
$\quad$ Thoracic & $4(7)$ & $21(17)$ & $0.40(0.15-1.12)$ & 0.07 \\
Abdominal & $1(2)$ & $17(14)$ & $0.12(0.02-0.91)$ & 0.01 \\
$\quad$ Extremities & $15(26)$ & $45(37)$ & $0.71(0.43-1.16)$ & 0.15 \\
Maxillofacial trauma & & & & \\
$\quad$ All injuries & $28(49)$ & $33(28)$ & $1.80(1.22-2.67)$ & 0.004 \\
Fractures alone & $10(18)$ & $5(4)$ & $4.2(1.5-11.8)$ & 0.006 \\
\hline
\end{tabular}

*Includes abrasions, minor contusions and sprains; †'Abbreviated Injury Scores: mild (none to moderate) and severe (severe to fatal)

findings which have been reported by others $(2,3,5)$. This is in keeping with collisions in which the front of the vehicle strikes the moose, knocking the animal's legs out and throwing its body over the hood of the vehicle into the windshield (2).

Although there was a higher rate of hospital admission for the control group, the injury severity and frequency of injury to most bodily regions was similar in the two groups. An increased frequency of abdominal injuries was seen in the control group. This may relate to a lower frequency of seatbelt use among controls. Of particular interest to this study is that the rate of maxillofacial injury in the moose group was almost two times greater than in the control group. Furthermore, the rate of severe facial trauma, involving maxillofacial fractures, was four times greater in the moose collision group. These findings are likely related to the animals' large body mass, high centre of gravity and propensity to travel over the hood into the windshield and front roof of the vehicle.

Our findings are in keeping with previous case series (1-5) suggesting that between $43 \%$ and $70 \%$ of the injuries sustained 
by victims of collisions with moose, elk or deer involve the face, head and neck. In contrast to previous studies, ours was a cohort study with comparison made to a control group of other high-speed motor vehicle collisions. Our findings suggest that the specific injury pattern in 'moose' collisions differs from other high-speed motor vehicle collisions in the relative overrepresentation of facial injuries (all types), specifically maxillofacial fractures.

Injury prevention strategies fall into the general categories of educational measures, engineering modifications, environmental modifications and legislative changes (14). One engineering strategy that may reduce the incidence of maxillofacial injury in these collisions is the airbag. Unfortunately, details of airbag presence and deployment were rarely mentioned in the charts in this particular study. One may also speculate that drivers of vehicles that are higher off the ground might be better protected from these types of injuries. Again, this information was not often available in our review of charts. These issues deserve attention in future research. Fencing along busy highways in some Canadian National Parks is an environmental modification designed to separate the vehicles from the animals and would be expected to reduce the frequency of collisions between the two. Unfortunately, the habitat of the animals extends much

\section{REFERENCES}

1. Rattey TE, Turner NE. Vehicle-moose accidents in Newfoundland. J Bone Joint Surg Am. 1991;73:1487-91. (Erratum in: J Bone Joint Surg Am 1992;74:456.)

2. Bjornstig U, Eriksson A, Thorson J, Bylund PO. Collisions with passenger cars and moose, Sweden. Am J Public Health 1986;76:460-2.

3. Farrell TM, Sutton JE, Clark DE, et al. Moose-motor vehicle collisions. An increasing hazard in northern New England. Arch Surg 1996;131:377-81.

4. Centers for Disease Control (CDC). Injuries from motor-vehicle collisions with deer - Kentucky, 1987-1989. MMWR Morb Mortal Wkly Rep 1991;40:717-9.

5. Eriksson A, Björnstig U, Thorson J. Collisions between cars and mooses: An analysis of collisions with fatal personal injuries. Travel Med Int 1985;3:130-7.

6. Species, Hunting in Alberta, Fish and Wildlife, Alberta Sustainable Resource Development, Alberta Government. $<$ www3.gov.ab.ca/srd/fw/hunting/s.html> (Version current at November 22, 2005).

7. St Anthony's Illustrated ICD-9-CM Code Book, 1999 edn. Reston: St Anthony Publishing Inc, 1998:E-4,E-5. beyond the boundaries of these fenced areas. In the present study, details of the location of the collisions (fenced versus unfenced areas) were inconsistently recorded on the charts. Future research should compare the numbers of collisions with animals in fenced and unfenced areas.

\section{CONCLUSIONS}

This retrospective cohort study, among patients presenting to a North American tertiary care trauma centre, compared injuries sustained by individuals involved in moose-motor vehicle collisions with injuries sustained by individuals in other high-speed motor vehicle collisions. Those involved in moose collisions had a significantly greater frequency of maxillofacial injuries and maxillofacial fractures, in spite of having a similar frequency of intracranial, spinal, thoracic and extremity injuries. This information may be helpful in the development of future prevention strategies aimed at this particular problem.

ACKNOWLEDGEMENTS: The authors acknowledge Kaaren Murray, Quality Improvement Health Information, Foothills Medical Centre, and Sukhi Lally, Health Record Services, Foothills Medical Centre.

8. Sun and Moon Rise/Set Tables, Herzberg Institute of Astrophysics, NRC. <www.hia-iha.nrc-cnrc.gc.ca/sunrise_e.html> (Version current at November 22, 2005).

9. US Naval Observatory. Earth's Seasons: Equinoxes, Solstices, Perihelion, and Aphelion, 1992-2005. Astronomical Applications Department. <http://aa.usno.navy.mil/data/docs/EarthSeasons.html> (Version current at September 21, 2005).

10. Rating the severity of tissue damage. I. The abbreviated scale. JAMA 1971;215:277-80.

11. StataCorp. Stata Statistical Software, Version 5.0. College Station, Texas: Stata Corporation, 1997.

12. Alberta Infrastructure and Transportation. Traffic Safety in Alberta: Statistics. <www.saferoads.com/about/statistics.html> (Version current at September 21, 2005).

13. Christie JS, Nason S. The UNB Transportation Group. Analysis of vehicle collisions with moose and deer on New Brunswick arterial highways. $<$ http://www.unb.ca/transpo/documents/MooseandDeerCollisions..03.pdf> (Version current at November 22, 2005).

14. Towner E, Carter Y, Hayes M. Implementation of injury prevention for children and young people. Inj Prev 1998;4(Suppl 4):S26-33. 